LAWRENCE LIVERMORE NAT IO N A L LABORATORY

Interaction Between Titanium Implant Surfaces and Hydrogen Peroxide in Biologically Relevant Environments

J. Muyco, T. Ratto, C.Orme, J. McKittrick, J. Frangos

April 22, 2004

MRS Spring Meeting 2004

San Francisco, CA, United States

April 12, 2004 through April 16, 2004 
This document was prepared as an account of work sponsored by an agency of the United States Government. Neither the United States Government nor the University of California nor any of their employees, makes any warranty, express or implied, or assumes any legal liability or responsibility for the accuracy, completeness, or usefulness of any information, apparatus, product, or process disclosed, or represents that its use would not infringe privately owned rights. Reference herein to any specific commercial product, process, or service by trade name, trademark, manufacturer, or otherwise, does not necessarily constitute or imply its endorsement, recommendation, or favoring by the United States Government or the University of California. The views and opinions of authors expressed herein do not necessarily state or reflect those of the United States Government or the University of California, and shall not be used for advertising or product endorsement purposes. 


\title{
Interaction Between Titanium Implant Surfaces and Hydrogen Peroxide in Biologically Relevant Environments
}

Julie Muyco ${ }^{1,2}$, Timothy Ratto ${ }^{1}$, Christine Orme ${ }^{1}$, Joanna McKittrick ${ }^{2}$, John Frangos ${ }^{3}$

${ }^{1}$ Chemistry and Materials Science, Lawrence Livermore National Laboratory, Livermore, CA 94550, U.S.A.

${ }^{2}$ Materials Science and Engineering Program, University of California, San Diego, La Jolla, CA 92093, U.S.A.

${ }^{3}$ La Jolla Bioengineering Institute, La Jolla, CA 92037, U.S.A.

\begin{abstract}
Titanium was exposed to dilute solutions of hydrogen peroxide $\left(\mathrm{H}_{2} \mathrm{O}_{2}\right)$ to better characterize the interaction at the interface between the solution and metal. The intensity of light passing through films of known thickness of titanium on quartz was measured as a function of time in contact with $\mathrm{H}_{2} \mathrm{O}_{2}$ in concentrations of $0.3 \%$ and $1.0 \%$. An atomic force microscope (AFM) was used to record deflection-distance (force) curves as a probe approached the interface of titanium in contact with solution containing $0.3 \%$ of $\mathrm{H}_{2} \mathrm{O}_{2}$. The interaction layer measured using AFM techniques was much greater than the thickness of the titanium films used in this study. Raman spectroscopy taken during interaction shows the emergence of a Ti-peroxy gel and titania after 2 hours in contact with $0.3 \% \mathrm{H}_{2} \mathrm{O}_{2}$ solution.
\end{abstract}

\section{INTRODUCTION}

Titanium has been widely used as an implant material due to its corrosion resistance and ability to osseointegrate, or to allow bone tissue to grow flush against the implant. These characteristics of titanium implants can be attributed to the oxide layer found on the surface. These studies aim to further the understanding of the role of the interaction between titanium implant surfaces and hydrogen peroxide in the ability of titanium implants to be accepted in the body. Hydrogen peroxide is produced in higher concentration during wound healing. Titanium interacts with hydrogen peroxide to make a Ti-peroxy gel (TiOOH): [1]

$$
\begin{aligned}
& 2 \mathrm{TiO}_{2}+\mathrm{H}_{2} \mathrm{O}_{2}+2 \mathrm{e}^{-} \rightarrow \mathrm{Ti}_{2} \mathrm{O}_{3}+\mathrm{H}_{2} \mathrm{O}+\mathrm{O}_{2} \\
& \mathrm{Ti}_{2} \mathrm{O}_{3}+\mathrm{H}_{2} \mathrm{O}_{2} \rightarrow 2 \mathrm{TiO}_{2}+\mathrm{H}_{2} \mathrm{O}+2 \mathrm{e}^{-} \\
& \mathrm{TiO}_{2}\left(\mathrm{H}_{2} \mathrm{O}\right)+\mathrm{H}^{+}+\mathrm{e}^{-} \rightarrow \operatorname{TiOOH}\left(\mathrm{H}_{2} \mathrm{O}\right)_{\mathrm{n}}
\end{aligned}
$$

The gel may serve many purposes that this study hopes to define. Among these are the ability to mediate reactive species produced during the wound healing process [2], influence the adhesion of proteins or the nucleation of bone mineral [3], and to serve as an intermediate layer that transitions mechanical properties between the stiff titanium and surrounding tissue.

Using AFM force curves, Raman spectroscopy and by observing changes in the optical properties of the material as a function of time exposed to hydrogen peroxide solution, the kinetics of the development of the Ti-peroxy gel as well as the mechanical properties of the gel can be determined. 


\section{EXPERIMENTAL METHODS}

Thin films of titanium were deposited on to quartz microscope slides obtained from G.M. Associates, Inc. (Oakland, California) using E-beam evaporation. Deposition thickness was monitored with a quartz crystal microbalance and varied from $10 \mathrm{~nm}$ to $50 \mathrm{~nm}$. Solutions of hydrogen peroxide were made from 30\% (8.8M) stock solution (VWR, Brisbane, California). Concentrations used ranged from $0.3 \%$ to $1.0 \%$.

\section{Light intensity and Raman spectra studies}

A micro-Raman spectrometer (Jobin Yvon, Inc., HR800, Sunnyvale, California) was used to supply the laser light to measure the intensity of light passing through a droplet of hydrogen peroxide solution on a titanium film of known thickness on quartz (time-lapse study) and simultaneously to take Raman spectra. As titanium interacts with $\mathrm{H}_{2} \mathrm{O}_{2}$, a pale yellow gel is formed that is transparent. The amount of laser light that passed through the film as measured by a photodiode increased over time until the film appeared transparent. The data obtained from the light intensity study yields the time for complete transformation of titanium of a known thickness to Ti-peroxy gel. Knowing the thickness of the titanium film, as measured using an AFM, the rate of transformation can be calculated.

Raman spectra were taken at 30-minute intervals for a collection time of 10 minutes. The spectra were used to verify the transformation of the titanium film to Ti-peroxy gel.

\section{$\underline{\text { AFM force curves }}$}

A Digital Instruments Dimension 3100 atomic force microscope (AFM) using $\mathrm{Si}_{3} \mathrm{~N}_{4}$ probes (NP-S probes, Veeco Metrology LLC, Santa Barbara, California) was used in contact mode to obtain force curves from titanium samples while exposed to hydrogen peroxide solutions. Force curves were collected during the first hour and 15 minutes of exposure of titanium to hydrogen peroxide. This time period corresponds to the early time periods of transformation of the titanium film to Ti-peroxy gel.

From the force curves, the thickness of the layer above the hard surface could be obtained. The thickness was based upon the point on the deflection-distance curve where deviation from no deflection began to the point where there was a sharp change in deflection. The hard surface begins where the slope of the force curve has a value of -1 . 


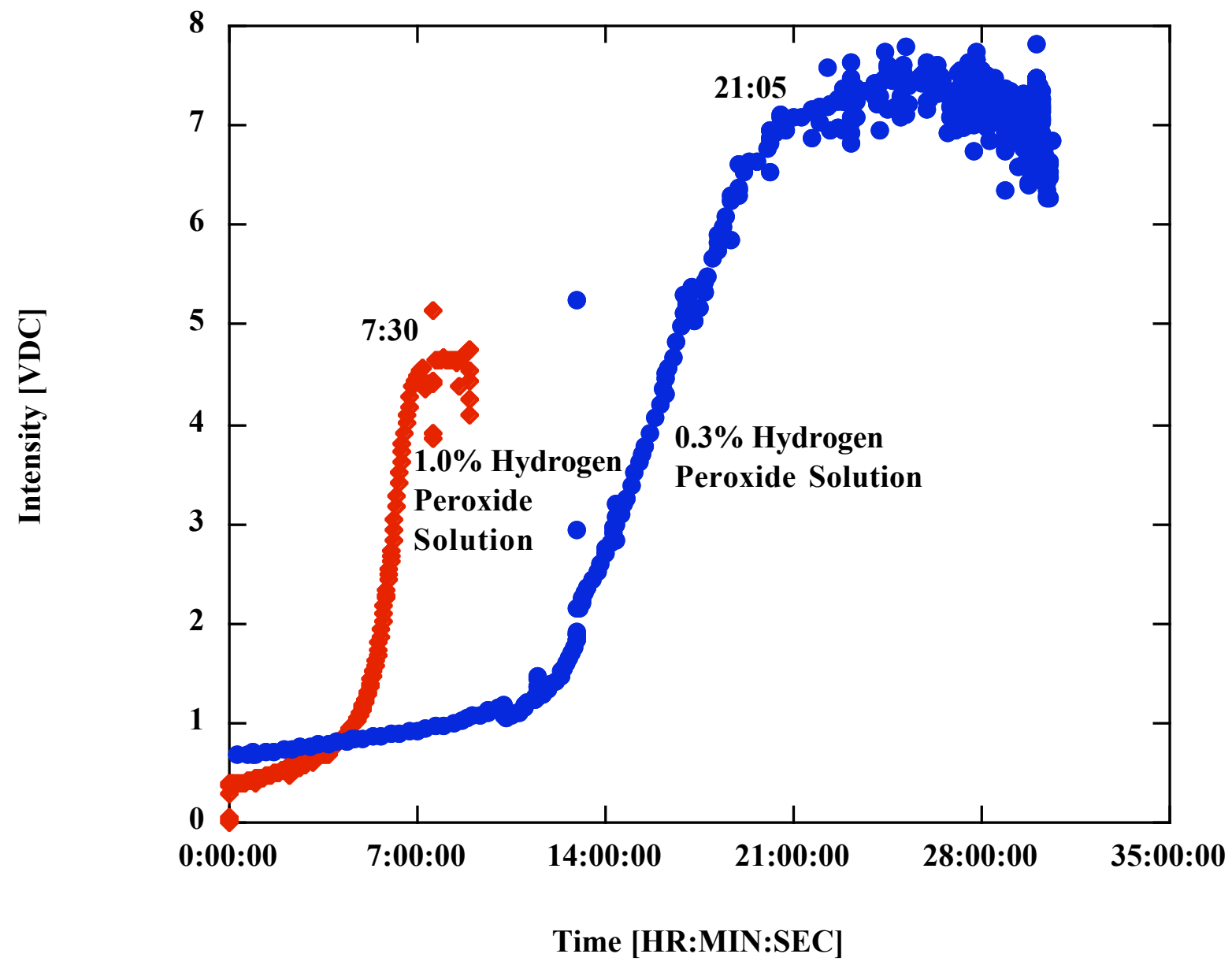

Figure 1. Shown is the change in intensity of light passing through $40 \mathrm{~nm}$ of titanium on quartz with exposure to $\mathrm{H}_{2} \mathrm{O}_{2}$ containing solution. The point when the curve has reached maximum intensity is taken as the time needed to convert the Ti film to transparent Ti-peroxy gel.

\section{RESULTS AND DISCUSSION}

\section{$\underline{\text { Light intensity study }}$}

Figure 1 shows the intensity as a function of exposure time to solutions containing hydrogen peroxide for $43 \pm 7 \mathrm{~nm}$ thick titanium films. The blue circles are from a solution containing $0.3 \%$ $\mathrm{H}_{2} \mathrm{O}_{2}$. The red diamonds are from a solution containing $1.0 \% \mathrm{H}_{2} \mathrm{O}_{2}$. Time for transformation of titanium to Ti-peroxy gel is taken to be where the intensity curves begin to reach a constant intensity. Maximum intensity varied possibly due to different neutral density filters used in the Raman instrument or that other factors played a role. Assuming that the full thickness of the titanium film was converted, the rates of transformation extrapolated are $0.096 \mathrm{~nm} /$ minute for $1.0 \% \mathrm{H}_{2} \mathrm{O}_{2}$ solution and $0.034 \mathrm{~nm} /$ minute for $0.3 \% \mathrm{H}_{2} \mathrm{O}_{2}$ solution. Assuming the rate is linearly dependant upon hydrogen peroxide concentration, these rates are in agreement with each other. 


\section{$\underline{\text { Raman spectra }}$}

The resulting Raman spectra are shown in figure 2 for a $34 \pm 9 \mathrm{~nm}$ thick titanium film in contact with $0.3 \% \mathrm{H}_{2} \mathrm{O}_{2}$. The peaks at 190,276 and $390 \mathrm{~cm}^{-1}$ correspond to Ti-peroxy gel [2]. The peak at $449 \mathrm{~cm}^{-1}$ can be attributed to rutile $\mathrm{TiO}_{2}$ while the peak at $670 \mathrm{~cm}^{-1}$ cannot at this time be attributed to any specific form of titania or Ti-peroxy gel. The peak at $821 \mathrm{~cm}^{-1}$ is attributed to background, possibly hydrogen peroxide. The blue line is the earliest spectrum recorded, the yellow taken during the middle of the experiment and the green was the last recorded. After approximately 2 hours, peaks corresponding to Ti-peroxy gel and titania begin to appear. As time increases, so do the intensity of these peaks, corresponding to increased material. The reduction in intensity after approximately 6 hours may be due lack of adjustment of the instrument for the moving interface of the sample in liquid as the Ti-peroxy gel layer grew.

Data for $10 \mathrm{~nm}$ thick films were not as clear due to reduced signal from the lower amount of sample.

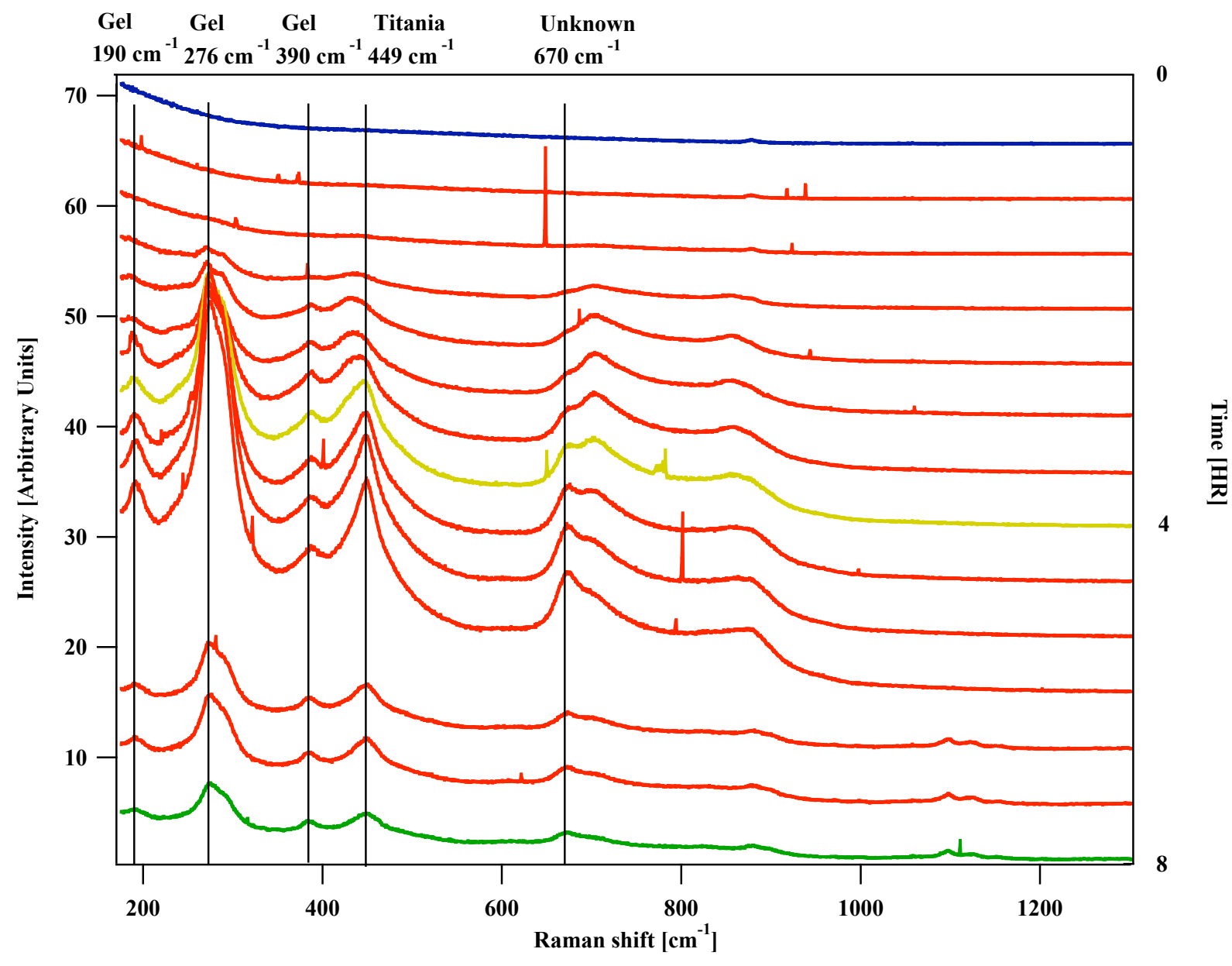

Figure 2. Raman spectra from 8 hours of exposure to $0.3 \% \mathrm{H}_{2} \mathrm{O}_{2}$ of an approximately $40 \mathrm{~nm}$ thick Ti film. The top spectrum is the earliest time point. Exposure time to $\mathrm{H}_{2} \mathrm{O}_{2}$ containing solution increases going down the right hand axis. Over time, peaks that can be attributed to Tiperoxy gel $\left(190,276\right.$, and $\left.390 \mathrm{~cm}^{-1}\right)$ and titania $\left(449 \mathrm{~cm}^{-1}\right)$ appear. 


\section{$\underline{\text { AFM force curves }}$}

Figure 3 shows representative deflection-distance curve evolution of a titanium film in contact with $0.3 \% \mathrm{H}_{2} \mathrm{O}_{2}$ solution as the AFM probe approached the surface. Far to the right, where the curve is relatively flat, corresponds to distances where there is no interaction between the tip and surface. As the probe approaches the surface, the slope of the curve changes from 0 to -1 when the hard surface is reached. The areas of the curve where the slope is not 0 or -1 correspond to other interactions between the surface and tip, such as a soft layer or attractive forces. The red curve is the earliest time point, followed by the purple, then orange, green, and finally yellow, taken at one hour and thirteen minutes after exposure to $\mathrm{H}_{2} \mathrm{O}_{2}$ began.

The force curves changed with time corresponding to a thickening of a layer above the hard surface. At early time points, represented by the red curve, an interaction layer forms, as indicated by the portion of the curve where the slope is not -1 or 0 . After about 7 to 10 minutes there appears to be the development of another layer. The initial layer can be interpreted as the

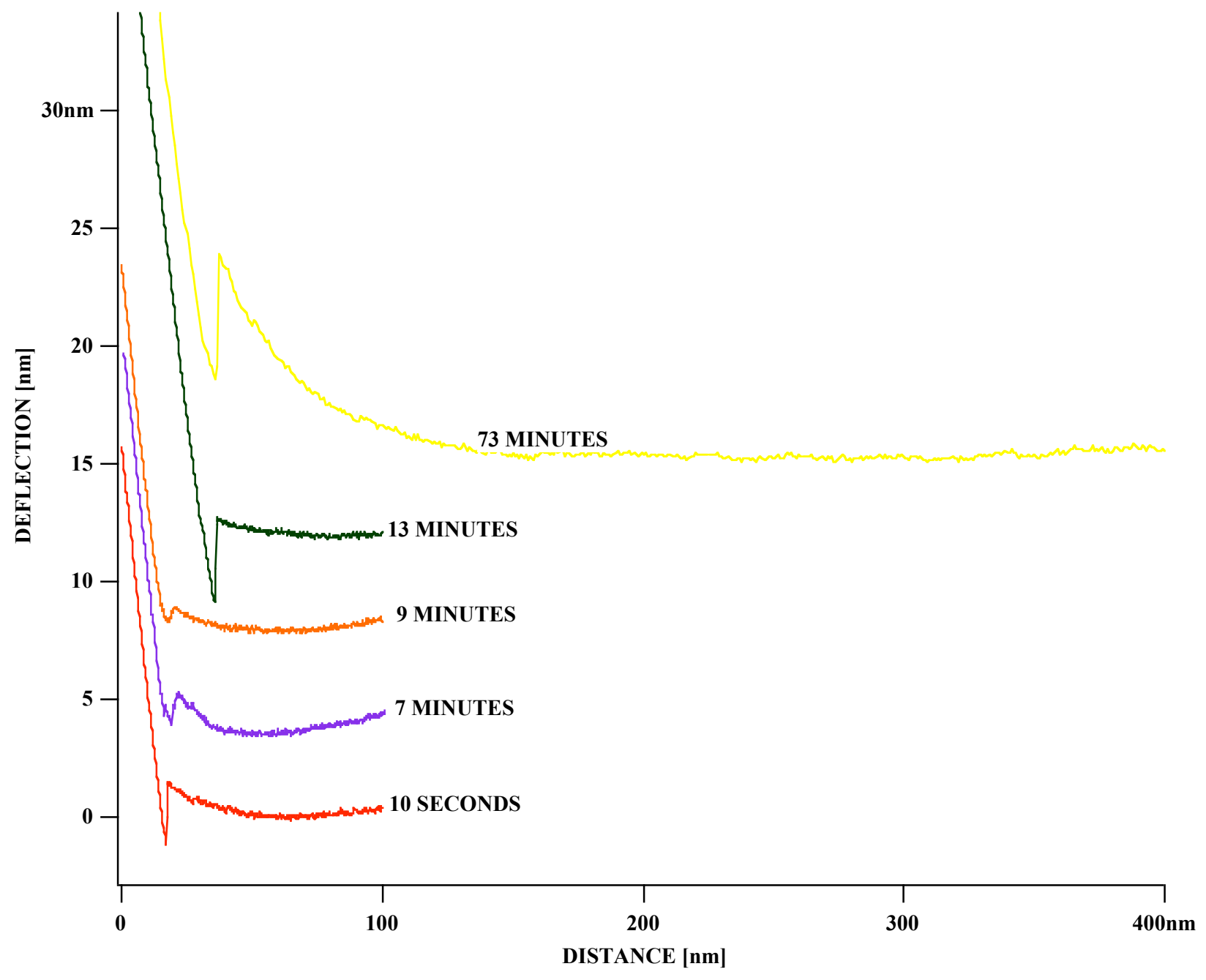

Figure 3. Force curves from titanium in contact with $0.3 \% \mathrm{H}_{2} \mathrm{O}_{2}$ solution. Only approach curves are shown. Representative data shown. 
depth of the Ti-peroxy gel layer. It is also possible that this layer is partially due to a repulsive Van der Waals force that is known to occur in certain liquids including hydrogen peroxide [4]. The degree to which repulsive forces contributed to the portion of force curve data attributed to the presence of a gel layer has not yet been determined. The secondary layer can be interpreted as either a denser layer under a more pliant layer or the accumulation of material on the AFM probe tip. At this time, it has not been verified if any material accumulates on the probe tip in a way that appears in the force curve data.

Using representative data taken at early and ending time points shows a growth rate of the Ti-peroxy gel layer versus time of approximately $0.767 \mathrm{~nm} /$ minute. This growth is significantly greater than the evolution rate calculated in the light intensity study. It should be noted, however, that the evolution of titanium into Ti-peroxy does not directly correspond to the growth of the gel on a surface since the volume of the gel will be greater than the volume of the original titanium being transformed.

\section{CONCLUSIONS}

The rates of transformation extrapolated from light intensity studies on approximately $40 \mathrm{~nm}$ thick titanium films are $0.096 \mathrm{~nm} /$ minute for $1.0 \% \mathrm{H}_{2} \mathrm{O}_{2}$ solution and $0.034 \mathrm{~nm} /$ minute for $0.3 \%$ $\mathrm{H}_{2} \mathrm{O}_{2}$ solution. AFM force curves show Ti-peroxy gel has an extrapolated growth rate of approximately $0.767 \mathrm{~nm} /$ minute in solution containing $0.3 \% \mathrm{H}_{2} \mathrm{O}_{2}$. It is not certain at this time whether repulsive forces add to the gel layer thickness, nor if there is material accumulating on the tip of the probe during force curve acquisition. Raman spectra showed that with $0.3 \% \mathrm{H}_{2} \mathrm{O}_{2}$ solution, Ti-peroxy gel formation is gradual and can be detected after 2 hours.

Further studies are required to verify the data presented here. Time correlated Raman and evolution of the titanium films will be done with concentrations of $\mathrm{H}_{2} \mathrm{O}_{2}$ closer to physiological concentrations. AFM force curves will be recorded under suitable circumstances to determine if the layer detected initially is indeed a Ti-peroxy gel layer.

\section{ACKNOWLEDGMENTS}

This work is performed as part of an NIH grant in conjunction with the La Jolla Bioengineering Institute. Appreciation is given to the SEGRF program at LLNL for support. This work was performed under the auspices of the U.S. Department of Energy by University of California, Lawrence Livermore National Laboratory under Contract W-7405-Eng-48. UCRLPROC-203710

\section{REFERENCES}

1. P. Tengvall, I. Lundström, L. Sjöqvist, H. Elwing and L.M. Bjursten, Biomaterials, 10, 166175 (1989).

2. P. Tengvall, T.P. Vikinge, I. Lundström, and B. Liedberg, J.Colloid and Interfacial Sci., 160, 10-15 (1993).

3. C. Ohtsuki, H. Iida, S. Hayakawa, and A. Osaka, J. Biomedical Materials Research, 35, 39-47 (1997).

4. B. Cappella, P. Baschieri, C. Frediani, P. Miccoli, and C. Ascoli, IEEE Engineering in Medicine and Biology, 16, 58-65 (1997). 